\title{
An interview with Professor John Evans
}

Question. As a member of the Institute's staff for many years and as former Director, how was your research directly affected by the bureaucratic and administrative commitments involved?

John Evans. Well I suppose progressively so. At first it was not really so bad because I was not Director and also the Institute was a far simpler place at that stage, with not nearly so much bureaucracy, so that I was in fact able to carry on fairly well and fairly normally; later on it got much more difficult because of various things, particularly of course taking over as Director at a time when bureaucracy was increasing enormously because of the pressure on funds. I think this is an inevitable dilemma in the universities at the present day. The pressures involved are much greater, the need for accountability has got much greater, and as a result if you take on what essentially is an administrative job like Director you find you are spending most of your time on that kind of activity. It is sad because it means a waste of good academic abilities.

Q. Looking back, would you have preferred to stay as just a member of staff rather than becoming Director?

J. E. Yes, a difficult one that really. In some ways, yes; on the other hand it is a question of the situation at the time. I was encouraged to stand for Director by various colleagues; I suppose the alternative was either to do that, or to face the possibility of somebody being brought in from the outside. I thought in that case I preferred to become Director myetif.

Q. Why was the Institute incorporated into UCL in 1986 and in what way has that affected its consequent development?

J. E. The immediate stimulus was the fact that we were under considerable financial pressure. It became obvious to me, and I think to most of us, that we simply were not big enough to cope with the new financial problems, and our prospects seemed to be going down. We would have had to lose a post every year or two and there seemed to be no way of reversing this. So that first of all made us think of going for the protection of a larger institution, and of course the University of London was quite keen on ourdoing that preferably with University College. There were other factors which came into consideration. Although the Institute enjoyed a lot of prestige and freedom as a small institution, once it took on undergraduates I felt it was a pity that they were not part of a larger, multifaculty institution which could give them a real, broad introduction to university life. I think this applies particularly in London, it might not apply in some other places such as Cambridge and some other University towns, but in London if you are on your own as a small institution, you tend to be isolated. 


\section{Q. Did the Institute benefit from the merger?}

J.E. I am sure that academically it has benefitted; also of course it has very much benefitted from the fact that it has more direct access to other disciplines which are essential to archaeology, and to the practitioners of those disciplines. It is much easier to obtain the sort of collaboration that we needed if you are part of the same institution than if you are going cap in hand to somebody outside. We did that and we still do to some extent, but it is nice to have a corps of people in the same college.

Q. Do you think that the Institute is still independent, in that it does very much its own thing, despite being part of UCL, or do you think that it is restrained politically by UCL?

J.E. Obviously there are constraints that were not there before, but I think on the whole it is remarkable how much freedom the Institute has within UCL. Certainly it was so until I left, and I think still is set-up to go its own way. Of course it has the great advantage of having its own building; that is a big thing, it gives you a real centre which is slightly outside the main college buildings and forms a focus. Of course the Institute too has always, in the past, been regarded by other archaeologists not just simply as part of London University but as THE Institute of Archaeology. For a long time it was the only place that called itself an Institute of Archaeology in Britain, and so they tended to come and use it as a sort of club, and I think that tradition has, to some extent, continued.

Q. The Institute has over the past months and years expanded rapidly, having recently incorporated the Egyptology, the Medieval and the Classics departments. How do you think the Institute is going to cope with this?

J. E. Well, I think physically the problem is obviously tremendous and the Institute building is too small to cope with all this. On the other hand, academically I think it is a very good thing indeed, and it was one of the reasons why I thought we would benefit from the union with UCL, because it was likely that this would bring almost all of archaeology in London University together. Originally, it's a historical problem. The Institute really came in a sense out of UCL. Sir Mortimer Wheeler, its founder, was a UCL graduate and a lecturer there later when he was Director of the London Museum. He started to get the Institute going within the framework of UCL, but he really wanted it to be outside, for what I think was at that time a very good reason, namely that archaeology was being stifled, he felt, by being attached to other disciplines, like classics and history, and he wanted it to be taken out so that it would have a chance to grow. So at that stage there was an advantage in being independent, but then he had to agree that the parts of archaeology that were already taught within UCL or elsewhere should stay there, so we could never develop these other branches and that was really in many ways a disadvantage to us. Habitually the Western Asia department have always felt they had that problem with Egyptology, since they have not been able to include that formally within their 
courses. The same situation really applies to the Roman set-up. The chair that Wheeler eventually took up in the Institute af ter the war had to be called the Chair of the Archaeology of the Roman Provinces, and this was because of the existing Yates Chair at University College (Classical Archaeology), which theoretically covered both Greek and Roman, so you could not include 'Metropolitan Rome' which was with University College. You could not have that. So this nonsense had to be set up, whereby you distinguished the Roman Provinces from Rome and Italy, and this has been felt as more and more of a constraint by successive incumbents. What happened with the Yates Chair was that it became, in effect, a chair of Greek archaeology. We had the Roman side, but it had to be called Roman Provinces. Now the two have come together. I know that some people have been unhappy with that but from my point of view it is an advance.

Q. As an archaeologist you know that there are always problems with funding. How would you describe the general funding climate in archaeology at the present, and the reasons for it?

J.E. Well, it depends where of course. I think the climate varies a certain amount from country to country; some countries do better than others. On the whole there has been a tendency, naturally, over the past years, with recession, for funding to get tighter; and also with political moves to the right - this tends to produce a tighter climate for funding. In this country I would say that we have had a great change in funding British archaeology because up until some years ago there was considerable expenditure by the Directorate of Ancient Monuments (now English Heritage) on rescue excavation, and gradually that has changed. First of all a lot of funding was switched to publication because there was such a tremendous backlog in that area; we have now moved on to a situation where the national funds are going mainly toconservation; there is now more emphasis on conservation, rather than excavation. This is something which has happened in other countries too where they too have been moving that way also. It has happened very strongly here; and this is coupled with the shifting of responsibility for funding mainly rescue excavation to developers. The national funds do not pay for it, but the developers do, so this means that the rescue archaeology units which were originally funded by the govemment had to fend for themselves as business operations, which necessitated a change in approach. Instead of the academic approach having priority, of necessity now it has to be a business approach and you have to look for a compromise between the amount of work you can reasonably ask the developers to fund and the amount of delay you can reasonably ask them to grant. It has become a rather difficult equation. This emphasis on conservation is certainly happening in other countries also, as I've said, and is quite a good thing really in discouraging excavation simply for the sake of excavation. In this country grant-making bodies now ask applicants who are proposing research excavations first of all the questions they think they are going to answer, secondly for a detailed plan of excavation, and a programme, and thirdly, more recently, press them hard on the question of how and when they intend to write it up and how they conceive they are going to get the report published. In fact, really, to have a complete plan from beginning to end. The 
British Academy has been doing this in recent years. This emerged as the big problem on the rescue side too where, incredibly, the old Ministry of Works for years went on paying people to excavate sites, but not to publish them. So those who were depending on this for a living had to move from one site to another accumulating an enormous backlog of past digs to publish, and of course those whowere not depending on it, people with jobs in museums or academics, tended to be also rather undisciplined in this respect and of ten liked to go on to a new dig in preference to writing up the old one. A natural human tendency! It is very difficult to control but there are at least attempts now being made fairly widely to tackle the problem.

Q. In 1975 you gave a speech at the Institute in which you stated that archaeology is a misunderstood subject. Do you think this still holds true, whose fault is it, and why?

J. E. Yes, I think it is to some extent still true. Obviously archaeology has got a lot of publicity in recent years but not always the right publicity, the best publicity. I think perhaps it is the fault of us as archaeologists to some extent in getting it over to the public. We have tended to be too oriented towards the academic side and less to publicising the subject to others. Some of the publicists have been good, but others have presented a very distorted image.

Q. In what way has this distorted image been presented?

J. E. I think there is quite a lot of coverage which still presents archaeology in terms of treasure hunting, virtually. Need I go further than the Indiana Jones films! You could not get a more naive presentation than that. Also there is a lot of writing which portrays archaeology in a rather superficial way. I am prepared to go a long way with popularisation. One has to do certain things to get points across to the public, but it is much better if it is done by people who have a competent knowledge of, and care for the subject rather than by those who may not.

Q. Archaeologists have a problem publicising and making archaeology available to the general public. The attitudes and teaching of the general public has to be changed so that they really understand what archaeology is about.

J. E. I think this is absolutely true. I think that we have to get people into archaeology who are going to be the future publicists and so the courses need to be broad and sometimes integrated with other subjects so that you can get people who do not necessarily want to become professional archaeologists, but who would come out with a sound knowledge of the subject. If they want to write in the area of archaeological publicity then they have the background to do so. This has happened in the past, but is something that we ought to foster more.

Q. Do you recognise archaeology as a mere collection of different disciplines and techniques for the retrieval of information, or, on the other hand, as a discipline in its own right with its own independent criteria? 
J. E. I take the view that it is a discipline in its own right with its own criteria. I have always taken this view and I have expressed it in various places.

Q. Don't you think that this may be changing, and that archaeology is now encompassing many other disciplines?

J. E. It always did, theoretically if not always in practice. That was one of the things that the Institute was set up for, to bring these disciplines in. On the other hand it presents us with a very considerable problem, because you cannot be an expert on every single subject. So in a sense this fragments the discipline. Either you get in experts from outside, or you train up your experts from the inside, as we try to do at the Institute on a small scale. Either way you get a certain fragmentation, and I think the answer is really that one person cannot be expectod to encompass the whole of archaeology; it has got to be a team effort with a number of people from different backgrounds co-operating to produce a total result. I do not see any other solution.

\section{Q. What is your idea of a 'complete archaeologist'?}

J.E. From my point of view a complete archaeologist is someone who has had a training in the subject as a discipline; that means grounding in the methodology as well as training in a particular field. Also it means someone who has had enough instruction in various related disciplines to know what he can get out of them - what he can expect other specialists to produce for him. It seems to me that is the essence. He has to be someone who has a good grasp of the discipline of archaeology as such, which means not only field work but also the way to integrate results from field work and also to incorporate the external information that is coming not only from the theoretical framework, but also the information coming from the various specialists. That, for me, is a complete archaeologist.

Q. There are people who had good excavation skills and were in continuous contact with the ground such as local workers etc. who have good knowledge of stratigraphy, soil formation etc. Would you not call those people archaeologists in their own way just as much as someone who teaches most of the year and excavates for a month or so every year?

J. E. Yes, I see your point. Yes, someone who is in the field to that extent can develop a very great feel for everything to do with excavation, survey, and the actual practical fieldwork. On the other hand he or she may not be able to do much in the way of interpreting, unless they havesome academic background as well. You've got to have the two things. Again, I think that this is something that, in the earliest stages particularly, the Institute was set up to try and do. Sir Mortimer Wheeler had various people who were working for him in the early days, the 1930s, who were getting considerable experience in excavating but sometimes had no academic training at all, and one of the ideas of having a diploma at the Institute rather than a degree in those early days, was to get some of these people in, train them up in the more theoretical and academic aspects of 
archaeology and then send them back to the field. There are far more opportunities now for people who come in that way to go and get degrees. At that time there was prehistoric archaeology at Cambridge, and in London, and there was classical archaeology in a few places; that was about it. Now in this country alone you've got about 30 universities teaching archaeology. So it is much easier for people who start as field workers to get the academic training.

Q. Would you say that the main task, or one of the main tasks, for an archaeologist is to be directly involved with fieldwork?

J. E. I certainly would not regard anyone as a really good archaeologist unless they had a real experience - and a feel - for the situation on the ground. On the other hand I think we have to admit that there must be different types of people, some who are more devoted to fieldwork, to producing new data and publishing it, and who perhaps are not particularly interested in going further than that, whether they have the ability or not. Others you find are much more interested in drawing the threads together from what is excavated in the field, interpreting them, going into the theoretical aspects and so on. I think you need both of these types of people, as you need also the people who are more interested in publicising archaeology. Part of the idea of the Institute was trying to raise archaeology to the status of a profession in this country, and I've always felt that was a good thing, but on the other hand it can have its dangers too. I think one doesn't want to get too immersed in a grey professionalism which while it may be all right for some professions is not very good for a discipline like archaeology. Essentially the whole point of archaeology is to disseminate the results to the public at large, to as many people as possible. You've got to really cater for the whole range and I think for that you need a lot of different kinds of people, and no doubt different kinds of courses.

\section{Q. Do you think that there is enough emphasis in courses on field methods?}

J. E. It has improved an enormous amount in recent years. There are many courses now, particularly at MA level, on field methods. There are more difficulties at undergraduate level and I think this varies enormously, both within this country and abroad, from one institution to another. We have always tried to include a fairly strong element of this at the Institute, and so have some other departments, but at others again there is still much less.

\section{Q. Would you say that the Institute needs more field method courses at undergraduate level?}

J. E. Well I would hesitate to pronounce at this stage. I am not sufficiently in touch with what is going on at the Institute now. I think there is always room for improvement. Looking back to when I came into archaeology at Cambridge there was very little training in field methods or anything of that sort. Of course the Institute was founded with the idea that field methods would be central; now whether they have always been as central as was originally intended I'm not so sure. 
Q. Quoting you again, you once said there was a 'sterile scientism' in archaeology based on typological sequences and the subdivision of phases. Do you feel this is still true?

J. E. Well, that was to some extent reacting against my own past, bocause when I came to archaeology that still seemed to be the essential task in prehistory, to establish the sequences. You had to get the framework; and then of course it went too far and it became an end in itself which it never should have been. Of course it became less important when you began to get the impact of absolute dating methods like ${ }^{14} \mathrm{C}$ and so on and it became less of a problem. Really you can justify people aiming for that at a certain period because they more or less had to; otherwise they were dealing with a mass of material that was quite unorganised.

Q. Do you think that today the chronology provided by radiocarbon dates has reached a point of credibility?

J. E. I always felt a bit worried about ${ }^{14} \mathrm{C}$ dates. I wish there were more alternative techniques with which we could compare these. I think there are still far too few ${ }^{14} \mathrm{C}$ dates. Some areas are $\mathrm{OK}$, but others, are not so. It is worrying that it is all that we've got.

Q. Talking more about chronology, do you think there is a way out of the chronological straight-jacket that archaeologists have imposed on the evidence?

J. E. It is obviously artificial to put dates on little cultural boxes but it is difficult to think how else you would do it. Otherwise you then get a completely fluid situation which is very difficult to manipulate, especially when you come to compare different areas. You have to have to have some sort of method. I suppose the answer is really that as long as you recognise it as to some extent artificial you can use it, but you have to keep that in mind. I think obviously a lot of the problems in the past stem from unconsciously taking these little blocks too literally.

\section{Q. Do you think this 'sterile scientism' still applies to certain people?}

J. E. There is probably too much emphasis on it still in some quarters. Central and Eastern Europe was one area where they were far too wedded to it. It was very much part of the German tradition that had been built up and which they stuck to; and I think, as you say, in the Mediterranean there is still a tendency towards that traditional approach. The situation in this country is that the change has been very radical and very quick; unfortunately in many other areas it has not been so rapid. Things have changed tremendously. Look at any archaeological journal now. The number of articles you now find on such topics as society and power rather than on chronology and typology is very striking.

Q. Staying with Mediterranean archaeology and your relationship with the Institute, after your retirement there was a decline in Mediterranean archaeology. 
Only since this year when Ruth Whitehouse was appointed lecturer at the Institute is anyone teaching Mediterranean archaeology since your departure. Why do you think that such a decline happened?

J. E. I was worried when I left, I must admit, because I seemed to be the only person very much involved; John Nandris was to some extent, of course, but I was the main one. There seemed to be a gap that was appeaning there and I have been very encouraged since Ruth Whitehouse has been given a lectureship. Also there has been the appointment of an Aegean lecturer, Cyprian Broodbank, who I think will also have wider Mediterranean interests. I think now the prospects are really quite good.

Q. Do you think these new appointments will make it possible for students to work in those areas?

J. E. I do not know. I would have thought that Cyprian Broodbank is the sort of person who will probably start field work in the Mediterranean; I feel sure he is quite keen to do that. I do not know what Ruth Whitehouse's plans are now. Obviously she has been active in the Western Mediterranean and she would want to have student involvement, no doubt, if she does further fieldwork there.

Q. Given your experience in Mediterranean archaeology and particularly in island archaeology, do you consider that an island environment provides the best climate for the study of past human behaviour and if so why?

J. E. I would not go along with that $100 \%$. I think island communities are very useful for studying certain aspects of human behaviour and certain types of closed communities. I think it is also very important that you have studies of more open areas, of areas where you can observe the interrelations between different communities and so on. Of course there are also different kinds of closed communities; for instance, the community cut off by mountains which is isolated in that way; you can get different insights from that. I would not like to say that island environments were the sole interesting ones from that point of view.

Q. In Malta the earliest phase is in many ways associated with the Stentinello Culture in Sicily. Why do you think that Malta until the end of the Pleistocene (10,000 BP) does not have any evidence of Palaeolithic remains? Is this due to lack of research?

J. E. I think is due to the size of Malta largely. If you draw in the land bridge there is a vast area which is not there any more and you've got these tiny little islands. In the Palaeolithic you could have had people around somewhere on that land bridge who wouldn't have left any traces in Malta.

Q. Do you think the relationship with the Sicilian Stentinnello and Kronio phases was only based on an exchange of pottery? 
J. E. I always had the idea that, assuming these people were the first settlers, they actually came from Sicily with the whole of the cultural attributes of, probably, something like the Kronio culture $e_{2}$ and that it then fairly rapidly diverged, because obviously in the next two phases you don't have a strong linkage with Sicily. They become very individual, local, and then you have this very peculiar situation in the Zebbug period where you get a sort of rapprochement with Sicily again.

Q. Especially in the south eastern part, in the Syracuse area. While Sicilian people came to Malta during the Stentinnello period, it seems that in the Early Bronze Age the Maltese people came to Sicily.

J. E. Bernabò Brea and I have spent a long time arguing about this one, because I find it difficult to imagine the Tarxien cemetery people developing in Malta. It could be conceivable, but at the moment the evidence does not seem to me to support it, so I don't see them going that way. I rather see them going the other way. We have a very strong difference of opinion about this.

Q. You once said that evidence such as linguistics, philology, anthropology, etc., should be separated from archaeological arguments since they tend to obscure reasoning. Don't you think that they could be regarded as another piece of evidence that contributes to the general picture?

J. E. I think this needs a bit of elaboration because what I was doing there was criticising the old tradition of, e.g. Classical archaeology where you mixed your literary evidence, your philological evidence, your archaeological evidence; and you buttressed an archaeological argument with others from philology or from literary texts and produced a sort of rickety arrangement which usually turned out to be totally indefensible. I think that is completely discredited now. What I was really trying to say there, is what I think is accepted by most people, namely that when you are pursuing an archaeological argument you should pursue it on the basis of archaeological evidence; when you are pursuing another aspect of the argument, it should be in terms of whatever discipline is involved. This is not to say that you must not compare archaeological findings with the findings of any other discipline, but that you should avoid this mixing at an early stage which only weakens the argument rather than strengthens it.

Q. Of course, ethnohistorical data can greatly aid archaeology, but do you think that it is ever used properly, taking into account the background to the sources?

J. E. The essential thing is to use them correctly, and this is what I think people often did not do in the past. They confused things and produced a sort of mishmash which was not very valid. If you are careful to use your evidence correctly and make your historical argument on the basis of a historical text and your archaeological one on the basis of your archaeology, then you can start producing useful results. 
Q. Not so long ago archaeologists going to a different country and conducting research there would often return home with their finds and usually not return them. Now things have gone to the other extreme to the extent that you cannot take a single sherd out of many countries, but can we blame those countries?

J. E. No, I think one has got to understand the attitudes that stem from this background. I wouldn't want to condemn them on that basis, but I think it is important to try and foster the kind of approach which it is not going to say 'we belong to this country therefore everything should be done by us', and so on. I think this leads to a very narrow approach. What one really wants to foster is an international outlook. Obviously you desperately need regulation in these things. You can't allow a free-for-all. One does understand that, naturally, people looking at what has happened in the past get very uptight about it, but I think if this doesn't develop into a more collaborative international attitude then it tends to be very negative for archaeology in the end.

Q. Do you think that those early exploitations have led to a rather nationalistic approach on the part of those countries?

J. E. I think they have. It doesn't always work out that way but I think it tends to produce a certain attitude, at least in the beginning. It is one of those things that's got to be lived through, because of what went before. One hopes that gradually this will change to something more encouraging for conducting research. 